\section{Special offers at the one stop shop this spring}

UnoDent has launched its first

Endodontic Spring Promotion.

Offering a one stop shop for all the needs of the modern dental practice, the UnoDent comprehensive endodontic product range delivers uncompromising quality at competitive prices.

Offers from the wide range of UnoDent endodontic products featured in the Spring Promotion include:

- Buy two get one free on Rubber Dam Squares

- Buy three get one free on UnoDent Professional Gates Glidden Drills

- Up to $28 \%$ off Hand K Files and Hedstrom Files RA

- Buy two get one free on Gutta Percha and Paper Points.

The UnoDent Spring Promotion also covers a range of practice essentials, including cross infection control, consumables, general hygiene, masks and surface wipes.

All UnoDent products are designed and manufactured to exacting standards to guarantee high performance and exceptional reliability.

Next day delivery is available on items ordered before $6 \mathrm{pm}$ and UnoDent also offers a 28-day money back guarantee.

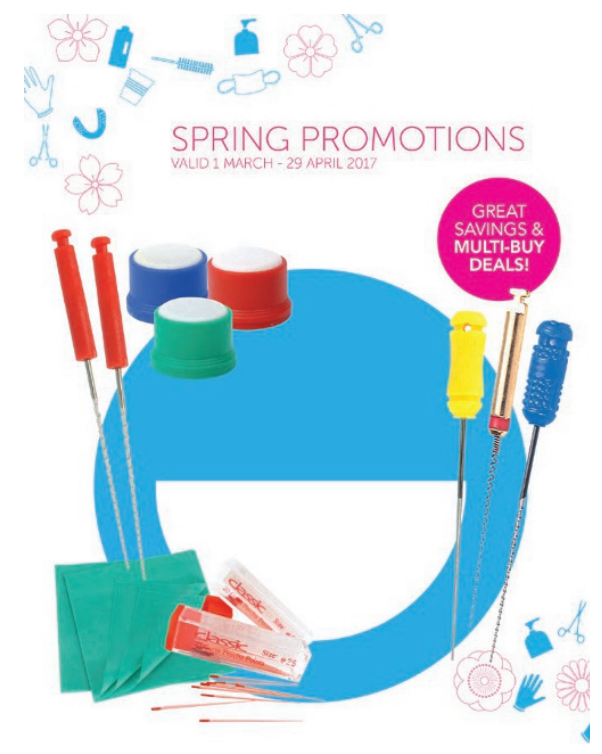

With 30 years of heritage, the full UnoDent range includes 3,000 product lines covering all practice essentials from amalgam through to X-ray envelopes.

To find out more about UnoDent's

Endodontic Spring Promotion, which is available to customers until 29 April 2017, call 0800585586 or visit www.dentaldirectory.co.uk.

Customers can also download the smartphone app, available with both Apple and Android.

\title{
Educational webinars with free verifiable CPD
}

The recent Colgate Sensitive Pro-Relief webinar held on 2 March 2017 provided an invigorating session on dentine hypersensitivity and your patients. The session provided guidance on how to overcome the challenges of patients with dentine hypersensitivity and how breakthrough technology in Colgate Sensitive Pro-Relief toothpaste can provide long-lasting relief from dentine hypersensitivity from the very first use (when toothpaste is applied directly to each affected tooth for one minute). To view the webinar and claim one hour verifiable CPD visit: www.colgateprofessional.co.uk/professional-education/videos/ dentine-hypersensitivity-and-your-patients-1-solution-3-benefits.

Colgate's next webinar on 27 April 2017 at 7:30 pm will help you understand how you can future-proof your patients' oral health with Colgate Total toothpaste. Speaker Dr Daniel Bachteler will approach oral health from the perspective of whole mouth health, acknowledging that oral health is about much more than just the absence of disease. To register for this upcoming webinar visit: www.colgateprofessional.co.uk/webinars.

The aim of the session is: To introduce the concept that oral health is more than the absence of disease and explain how Colgate Total can benefit your patients to achieve whole mouth bacterial control.

The learning outcomes are: to discuss the recent understanding of oral health; to understand the role of bacteria on oral hard and soft tissues; and to explore how Colgate Total can protect the future of your patients' oral health.

To join Colgate for this informative session where you will also qualify for free verifiable $\mathrm{CPD}$, register at: www.colgateprofessional.co.uk/webinars.

\section{Healthy discounts}

The Healthy Discounts scheme from Munroe Sutton is the perfect way to attract new patients to your practice. By agreeing to offer the $20 \%$ savings that are available to Healthy Discounts members, your practice can take advantage of an extensive pool of patients.

Becoming part of the Munroe Sutton network is absolutely free for dental practices and includes a list of fantastic benefits, including expert marketing advice, unrivalled support and enrolment to one of the UK's largest networks of healthcare, insurance and business institutions.

All you need to do to take advantage of this excellent package is to offer the Healthy Discounts in your practice - and see a vast selection of new patients book appointments with you in order to reap the benefits of exceptional, cost effective dental treatment. www.munroesutton.co.uk.

\section{Saving you time and hassle}

Improving upon its previously popular Multi-unit abutment, Nobel Biocare now offers the Multi-unit Abutment Plus.

Significantly reducing the chair time required to perform a denture conversion - often used for the All-on-4 treatment concept - the innovative solution streamlines the professional workflow while enhancing patient experience.

Featuring a snap-fit function between the temporary cylinders and the abutment, it eliminates the need for screws during the try-in process. This means the temporary cylinders and denture can be removed as many times as necessary during the conversion process without any of the time or hassle previously required to tighten and loosen screws every time.

One of the latest solutions in Nobel Biocare's extensive portfolio of leading implant products, the Multi-unit Abutment is a must-have for every implant dentist. It is available as part of a comprehensive system of solutions clinically proven to deliver effective and long-lasting results.

For more information, contact Nobel Biocare on 0208756 3300, or visit www. nobelbiocare.com. 